\title{
PIECES Framework untuk Analisa Tingkat Kepuasan Pengguna dan Kepentingan Sistem Informasi
}

\author{
Syahri Ramadhani, Wahyu A. Kusuma \\ ${ }^{[1][2]}$ Universitas Muhammadiyah Malang \\ e-mail: Syahri.ramadhani@gmail.com
}

\begin{abstract}
Abstrak - Penelitian ini mencoba untuk menerapkan PIECES Framework pada analisis sistem infromasi. Untuk meerapkannya di perlukan untuk menguji respon pengguna pada suati sistem informasi, dan sistem yang akan di uji adalah SIM PKN milik Universitas Muhammadiyah Malang, PIECES berfokus pada 6 fokus analisis (performance, Information and Data, Economy, Control and Security, Effeciency, dan Service). Tujuan Penelitian ini adalah Pengaplikasian PIECES Framework dengan mengukur tingkat kepentingan dan kepuasan pada SIM PKN Teknik informatika UMM. Hasil Penelitian ini menunjukan bahwa Tanggapan pengguna tentang SIM PKN sangat baik dengan rata rata pada tingkat kepuasan sebesar 4.03 dan tingkat kepentingan sebesar 4.19.
\end{abstract}

Kata Kunci: PIECES, SIM PKN, Analisa sistem informasi

Abstract - This Paper try to apply PIECES Frameworn on System Infromation analysis. To realize it, we need to test user repond on one information system, we will try to test on SIM PKN, one of information system in Universitas Muhammadiyah Malang. PIECES Framework has 6 scope analysis (Performance, Information and Data, Economics, Control and Security, Effeciency, and Service).Our purpose is Apllyin PIECES framework to determined Satisfaction of user and Importance of the system on SIM PKN. This paper obtained result that show the research is done, and users response are very good with average of satisfaction 4,03 and importance of system 4,19.

Index Terms: PIECES, SIM PKN, Information System analysis

\section{Pendahuluan}

$\mathrm{P}$ PIECES Framework adalah sebuah kerangka yang di pakai untuk mengklasifikasikan suatu problem, opportunities, dan directives yang terdapat pada bagian scope definition analisis dan perancangan sistem, pada penelitian ini penulis mencoba untuk mengimplementasikan PIECES untuk tujuan evaluasi tingkat kepuasan dan kepentingan Sistem informasi, kali ini Penulis mengambil sebuah Studi Kasus pada Sistem informasi Praktek kerja nyata pada Universitas Muhammadiyah Malang.
Praktek Kerja Nyata (PKN) di Universitas Muhammadi-yah Malang adalah program praktek kerja di perusahaan/industri/instansi sebagai beban SKS yang harus diikuti oleh mahasiswa di lingkungan jurusan Teknik Informatika untuk melengkapi pengetahuan teori yang diperoleh di bangku perkuliahan.Pada prodi Teknik Informatika terdapat sistem yang mendukung proses PKN yaitu SIM PKN, SIM PKN adalah sebuah sistem informasi yang digunakan untuk mendukung proses Praktek kerja nyata di Teknik Infomratika 
UMM yang memungkinkan mahasiswa untuk lebih mudah melaksanakan PKN sehingga dapat mengisi laporan, melihat sertifikat secara online.

Untuk mengetahui tingkat kepuasan pengguna dan tingkat kepentingan penerapan SIM PKN, maka di perlukan proses analisis dan evaluasi terhadap pengguna tentang kinerja sistem tersebut. Evaluasi merupakan kegiatan terencana untuk menilai suatu permasalahan yang terjadi dengan menggunakan instrumen dan hasilnya dapat dibandingkan dengan tolok ukur untuk memperoleh kesimpulan sehingga ditemukan solusi untuk menyelesaikan permasalahan yang timbul. Sedangkan Evaluasi sistem informasi dapat dilakukan dengan cara yang berbeda dan pada tingkatan yang berbeda, tergantung pada tujuan evaluasinya. Tujuannya adalah untuk menilai kemampuan teknis, pelaksanaan operasional, dan pendayagunaan sistem [1]

Analisis Tingkat Kepuasan dan Kepentingan pada SIM PKN ini berfokus pada kinerja sistem, se-hingga focus analisis yang akan dilakukan adalah bagaimana pandangan pengguna terhadap kinerja sistem SIM PKN dari segi kepentingan sistem informasi dan kepuasan pemakaian pengguna.Metode yang digunakan adalah model analisis PIECES Framework seperti pada penelitian sebelumnya [2]. Untuk mempermudah analisi PIECES menawarkan focus ke 6 ana-lisi yaitu (performance, Information and Data, Economy, Control and Security, Effeciency, dan Service). Tujuan dari Penelitian ini adalah mengukur tingkat kepuasan dan Kepentingan penerapan sistem SIM PKN bagi pengguna

\section{Metodologi Penelitian}

\subsection{Jenis Penelitian}

Jenis Penelitian ini adalah deskriptif kuantitatif yang bertujuan untuk menggambarkan, meringkas, berbagi kondisi, berbagai situasi atau berbagai variabel yang timbul di masyarakat yang menjadi objek penelitian, dalam penelitian ini yang menjadi objek adalah Pengguna SIM PKN pada Teknik informatika

\subsection{Instrumen Penelitian}

Instrumen penelitian menggunakan kuisoner, yang akan menggali informasi tentang tingkat kepuasan dan kepentingan SIM PKN bagi para pengguna. Kuisoner ini di buat berdasarkan 6 fokus analisis dari PIECES Framework.Objek Penelitain ini adalah SIM PKN dan yang menjadi sumber penggalian data atau Sampel adalah para mahasiswa yang telah melaksanakan PKN dan telah menggunakan SIM PKN sebanyak 40 orang.

\subsection{PIECES Framework}

PIECES framework adalah kerangka yang dipakai untuk mengklasifikasikan suatu problem, opportunities, dan directives yang terdapat pada bagian scope definition analisis dan perancangan sistem. Dengan kerangka ini, dapat dihasilkan hal-hal baru yang dapat menjadi pertimbangan dalam mengembangkan sistem [2]. Dalam Pieces terdapat 6 variabel analisis yaitu : Performance, Information and Data, Economics, Control and Security,Effeciency, Service. Tabel 1-4 akan menjelaskan PIECES Framework yang digunakan dalam penelitan ini :

TABEL I

Domain PIECES Framework

\begin{tabular}{|l|l|l|}
\hline No & Variabel & Jumlah Pertanyaan \\
\hline 1 & Perfomrance & 5 \\
\hline 2 & Information and Data & 9 \\
\hline 3 & Economics & 3 \\
\hline 4 & Control and Security & 4 \\
\hline 5 & Efficiency & 3 \\
\hline 6 & Service & 5 \\
\hline
\end{tabular}

TABEL 2

Skala Tingkat Kepentingan

\begin{tabular}{|l|l|l|}
\hline Pilihan Jawaban & Singkatan & Skor \\
\hline Sangat Penting & SP & 5 \\
\hline Penting & P & 4 \\
\hline Ragu Ragu & RG & 3 \\
\hline Tidak Penting & TP & 2 \\
\hline $\begin{array}{l}\text { Sangat Tidak Pent- } \\
\text { ing }\end{array}$ & STP & 1 \\
\hline
\end{tabular}

TABEL 3

Skala Tingkat Kepuasan

\begin{tabular}{|l|l|l|}
\hline Pilihan Jawaban & Singkatan & Skor \\
\hline
\end{tabular}




\begin{tabular}{|l|l|l|}
\hline Sangat Setuju & SS & 5 \\
\hline Setuju & S & 4 \\
\hline Ragu ragu & RG & 3 \\
\hline Tidak Setuju & TS & 2 \\
\hline Sangat Tidak Setuju & STS & 1 \\
\hline
\end{tabular}

TABEL 4

Rata-rata kepuasan dan kepentingan

\begin{tabular}{|l|l|l|}
\hline $\begin{array}{l}\text { Range } \\
\text { Nilai }\end{array}$ & $\begin{array}{l}\text { Predikat Kepent- } \\
\text { ingan }\end{array}$ & $\begin{array}{l}\text { Predikat Kepua- } \\
\text { san }\end{array}$ \\
\hline $1-1.79$ & $\begin{array}{l}\text { Sangat Tidak } \\
\text { Penting }\end{array}$ & $\begin{array}{l}\text { Sangat Tidak } \\
\text { Puas }\end{array}$ \\
\hline $\begin{array}{l}1.8- \\
2.59\end{array}$ & Tidak Penting & Tidak Puas \\
\hline $2.6-$ & Cukup Penting & Cukup Puas \\
\hline 3.39 & & Puas \\
$4.4-$ & Penting & Sangat Puas \\
\hline $4.92-5$ & Sangat Penting & \\
\hline
\end{tabular}

\subsection{Pengumpulan data}

PIECES framework adalah kerangka yang dipakai untuk Pengumpulan data di lakukan dengan Teknik observasi, yaitu dengan menyebarkan daftar pertanyaan kepada para mahasiswa Teknik informatika yang telah menggunakan SIM PKN pada pelaksanaan praktek kerja nyata.Daftar Pertanyaan dibuat dengan menggunakan domain PIECES Framework yang dapat di lihat pada tabel 1 .

\subsection{Metode analisis Data}

Data yang didapatkan dari kuisoner akan di Analisa menggunakan skala likert. Skala likert ini merupakan skala yang dapat dipergunakan untuk mengukur sikap, pendapat, dan persepsi seseorang atau sekelompok orang mengenai suatu gejala atau fenomena [4]. Pada evaluasi skala ini digunakan untuk menilai keberhasilan, manfaat atau mengetahui kepuasan pengguna suatu kebijakan atau program.
Untuk mengetahui tingkat kepuasan dan kepentingan sistem informasi pada SIM PKN rumus yang digunakan menurut metode likert (Nugraha, Harsono \& Adianto, 2014) adalah :

$$
R S K=\frac{J S K}{J K}
$$

$\mathrm{RK}=$ Rata-rata kepuasan/kepentingan

JSK $=$ Jumlah skor kuisoner

$\mathrm{JK}=$ Jumlah Kuisoner

\section{Hasil dan Pembahasan}

Berikut ini adalah hasil dan pembahasan penelitian yang telah di lakukan sesuai dengan metodologi penelitian

\subsection{Instrumen Penelitian}

Pada Instrumen Penelitian menggunakan daftar pertanyaan yang dapat dilihat pada tabel 5 .

\subsection{Perhitungan dan Analisis Data}

Dengan persamaan rata rata kepentingan dan kepuasan di atas, dan data yang telah di kumpulkan dari 40 responden di peroleh rata rata tingkat kepuasan dapat di lihat pada tabel 6 dan tabel 7.

\section{TABEL 6}

Tabulasi kuesioner tingkat kepuasan pengguna SIM PKN

\begin{tabular}{|l|l|l|}
\hline Domain & Rata Rata & Predikat \\
\hline Performance and & 4,21 & Puas \\
\hline $\begin{array}{l}\text { Information } \\
\text { Data }\end{array}$ & 4,03 & Puas \\
\hline Economy and Secu- & 4,11 & Puas \\
\hline $\begin{array}{l}\text { Control } \\
\text { rity }\end{array}$ & Puas \\
\hline Effeciency & 4 & Puas \\
\hline Service & 3,95 & Puas \\
\hline
\end{tabular}

TABEL 7

Tabulasi kuesioner tingkat kepuasan pengguna SIM PKN

\begin{tabular}{|l|l|l|}
\hline Domain & Rata Rata & Predikat \\
\hline Performance & 4,21 & Penting \\
\hline $\begin{array}{l}\text { Information and } \\
\text { Data }\end{array}$ & 4,21 & Penting \\
\hline Economy & 4,26 & Penting \\
\hline Control and Security & 4,17 & Penting \\
\hline Effeciency & 4,23 & Penting \\
\hline Service & 4,08 & Penting \\
\hline
\end{tabular}




\subsection{Analisa Tingkat kesesuaian kepentingan dan kepuasan pengguna SIM}

Berdasarkan Hasil yang didapat dari pengukuran 40 orang responden,maka akan di hasilkan suatu perhitungan mengenai tingkat kepuasan dan kepentingan penggunaan dan penerapan SIM PKN. Metode yang digunakan adalah deskriptif kuantitatif dengan menggunakan importanceperformance analysis (IPA). Penggunaan metode importance performance analysis adalah dalam mengukur tingkat kepuasan pelayanan jasa yang masuk pada kuadran-kuadran pada peta importance performance matrix [5]. Dalam metode ini diperlukan pengukuran tingkat kesesuaian untuk mengetahui tingkat kepuasan pengguna terhadap sistem in-formasi DJP online. Rumus yang digunakan adalah sebagai berikut :.

$$
T k i=\frac{X i}{Y i} \times 100 \%
$$

TKI $=$ Tingkat Kesesuaian Responden

$\mathrm{Xi}=$ Skor rata rata kepuasan

$\mathrm{Yi}=$ Skor rata rata kepentingan

Setelah di hitung maka diperoleh hasil sesuai gambar 1, dan kemudian akan di jelaskan pada tabel 8 .

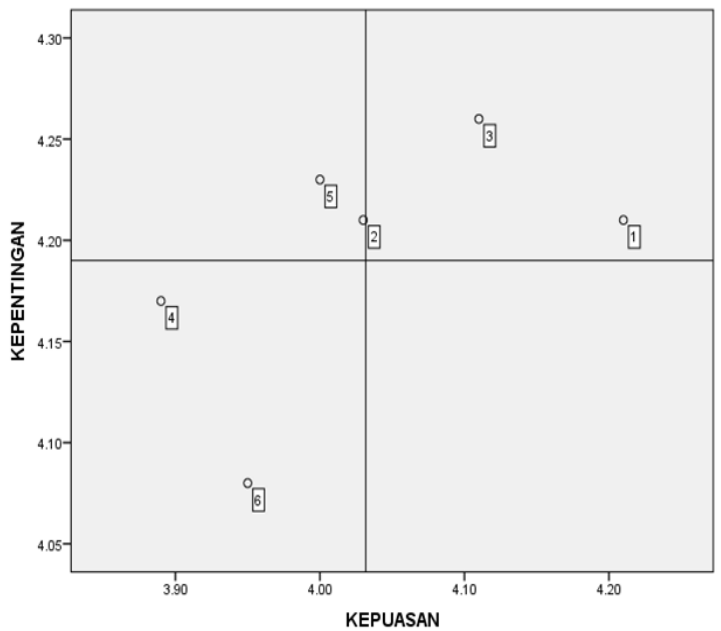

Gambar 1. Diagram Importance - performance Analiysis (IPA)

TABEL 8

Hasil Analisa

\begin{tabular}{|l|l|l}
\hline Domain & Hasil Perhitungan & Keterangan \\
\hline
\end{tabular}

\begin{tabular}{|l|l|l|}
\hline Performance & $100 \%$ & $\begin{array}{l}\text { Pertahankan Pres- } \\
\text { tasi }\end{array}$ \\
\hline $\begin{array}{l}\text { Information } \\
\text { and Data }\end{array}$ & $95,72 \%$ & Prioritas Utama \\
\hline Economics & $96,48 \%$ & $\begin{array}{l}\text { Pertahankan Pres- } \\
\text { tasi }\end{array}$ \\
\hline $\begin{array}{l}\text { Control and } \\
\text { Security }\end{array}$ & $93,29 \%$ & Prioritas Rendah \\
\hline Efficiency & $94,56 \%$ & Prioritas Utama \\
\hline Service & $96,81 \%$ & Prioritas Rendah \\
\hline
\end{tabular}

a. Pertahankan Prestasi

Menggambarkan bahwa Faktor yang mempengaruhi kepuasan dan kepentingan sudah baik dan harus di perthankan. SIM PKN sudah dapat meningkatkan efisiensi dan efektivitas dalam Pengerjaan PKN, pengguna juga sudah merasakan kepuasan terhadap SIM PKN.

b. Prioritas Utama

Menggambarkan bahwa faktor yang mempengaruhi kepuasan pengguna dan kepentingan penerapan SIM PKN yang perlu diprioritasikan, domain yang memiliki nilai ini dianggap penting namun pengguna belum terlalu merasakan kepuasan dari domain tersebut.

c. Prioritas Rendah

Menggambarkan bahwa faktor yang mempengaruhi kepuasan pengguna dan kepentingan penerapan SIM PKN yang dikategorikan prioritas rendah, dalam penerapan SIM PKN nilai yang mempunyai status ini tidak terlalu penting, pengguna belum merasakan kepuasan terkait nilai tersebut

\section{SESI AKHIR}

\subsection{Kesimpulan dan Saran}

Berdasarkan hasil perhitungan data terhadap 40 orang pengguna SIM PKN yang telah menyelesaikan PKN dan analisis terhadap tingkat kepuasan dan kepentingan penerapan sistem SIM PKN, maka dapat disimpulkan bahwa sistem telah mampu untuk mem-berikan kepuasan pengguna dan di anggap penting dalam penerapannya karena dianggap memudahkan proses praktek kerja nyata di Teknik informatika, namun tetap diperlukan adanya perbaikan dan 
pengem-bangan lebih lanjut untuk menutupi kelemahan dan kekurangan yang terdapat di SIM PKN untuk kedepannya.

\section{UCAPAN TERIMAKASIH}

Penulis bersyukur kepada Allah SWT karena telah mengizinkan penulis untuk menyelesaikan penelitian ini dan Mengucapkan terimakasih kepada para rekan rekan yang membantu serta dosen pembimbing yang membimbing saya untuk menyelesaikan penelitian ini dan para responden yang telah bersedia mengisi kuisioner hingga tercapai nya penelitian ini.

\section{REFERENSI}

[1] Tullah, Rahmat. Hanafri, Muhammad Iqbal. (2014). Evaluasi Penerapan Sistem Informasi Pada Politeknik LP3I Jakarta Dengan Metode Pieces. ISSN: 2088-1762. Jakarta: Jurnal Ilmiah Kursor Vol 1/Maret 2014: 22-28

[2] Supriyatna, Adi. Maria, Vivi. (2017). Analisis Tingkat Kepuasan Pengguna dan Tingkat Kepentingan Penerapan Sistem Informasi DJP Online dengan Kerangka PIECES. ISSN: 2477-698X. KHAZANAH INFORMATIKA Vol. 3 No. 2 Desember 2017

[3] Nazir, Moh. (2014). Metode Penelitian. Jakarta: Ghalia Indonesia

[4] Nugraha, Rizal. Harsono,Ambar. Adianto,Hari. (2014). Usulan Peningkatan Kualitas Pelayanan Jasa pada Bengkel "X" Berdasarkan Hasil Matrix ImportancePerformance Analyisi (Studi kasus di Bengkel AHASS PD. Sumber Motor Karawang). Jurnal Online Institut Teknologi Nasional Vol. 01 No. 03 Januari 2014: 221-231

[5] C. M. N. Faisal, M. Gonzalez-Rodriguez, D. FernandezLanvin, and J. De AndresSuarez (2017) .Web Design Attributes in Building User Trust, Satisfaction, and Loyalty for a High Uncertainty Avoidance Culture. IEEE Trans. Human-Machine Syst., vol. 47, no. 6, pp. 847 859, 2017

[6] Rahimi, Mohammad. Armand Baboli. Yacine Rekik.(2014). A bi-objective inventory routing problem byconsidering customer satisfaction level in context of perishable product. IEEE Symposium on Computational Intelligence in Production and Logistics Systems (CIPLS). 91-97

[7] S. M. H. Mahmud, A. Kabir, O. A. M. Salem, K. Ntikurako, and G. Fernand.(2016). The Comparative Analysis of Online Shopping Information Platform ' s Security Based on Customer Satisfaction. no. 2012, pp. 157-161, 2016 


\section{TABEL 5}

Daftar Pertanyaan Kuisioner

\begin{tabular}{|c|c|c|}
\hline No & Domain & Pertanyaan \\
\hline 1 & Performance & $\begin{array}{l}\text { a. Sistem informasi pkn teknik informatika umm mudah diakses oleh pengguna. } \\
\text { b. Sistem informasi pkn teknik informatika umm dapat mengoperasikan sejumlah } \\
\text { perintah dalam waktu yang relatif singkat, tanpa mengalami hambatan. } \\
\text { c. Sistem informasi pkn teknik informatika umm dalam merespon suatu perintah } \\
\text { pembatalan maupun permintaan terhadap suatu proses dapat dilakukan dengan } \\
\text { cepat. } \\
\text { d. Pada saat sistem informasi pkn teknik informatika umm digunakan secara bersa- } \\
\text { maan, kinerja sistem informasi harus tetap berjalan stabil. } \\
\text { e. Total waktu yang dibutuhkan dalam melakukan pengolahan data hingga } \\
\text { menghasilkan informasi harus dapat dilakukan dengan cepat. }\end{array}$ \\
\hline 2 & $\begin{array}{l}\text { Information } \\
\text { and data }\end{array}$ & $\begin{array}{l}\text { a. Data yang disimpan oleh sistem informasi pkn teknik informatika umm harus } \\
\text { tersimpan sesuai dengan yang dimasukkan kedalam sistem } \\
\text { b. Sistem informasi pkn teknik informatika umm tidak dapat menyimpan data yang } \\
\text { bukan seharusnya. } \\
\text { c. Data yang mengandung kesalahan atau data yang tidak benar tidak dapat disim- } \\
\text { pan oleh sistem informasi pkn teknik informatika umm. } \\
\text { d. Sistem informasi pkn teknik informatika umm tidak dapat menyimpan data yang } \\
\text { sama sehingga tidak menimbulkan duplikasi atau redudansi data. } \\
\text { e. Informasi yang dihasilkan oleh sistem informasi harus sesuai dengan yang dibu- } \\
\text { tuhkan. } \\
\text { f. Format informasi yang dihasilkan oleh sistem informasi pkn teknik informatika } \\
\text { g. Data yang diolah oleh sistem informasi pkn teknik informatika umm harus ter- } \\
\text { s. } \\
\text { h. Informasi yang disajikan sistem informasi pkn teknik informatika umm mudah } \\
\text { i. untuk dipelajari dan dipahami. } \\
\text { Informasi yang dihasilkan sistem informasi pkn teknik informatika umm dapat } \\
\text { diandalkan /dipercaya. }\end{array}$ \\
\hline 3. & Economics & $\begin{array}{l}\text { a. Sistem informasi pkn harus dapat mengurangi biaya mahasiswa dalam } \\
\text { mengerjakan praktek kerja nyata } \\
\text { b. Ada perubahan yang signifikan dalam hal perkembangan proses pkn menjadi } \\
\text { lebih baik dengan adanya sistem informasi pkn teknik informatika umm. } \\
\text { c. Bentuk pengamanan yang terdapat pada sistem informasi pkn teknik informatika } \\
\text { umm dapat menjaga data atau informasi dari berbagai bentuk kecurangan atau } \\
\text { kejahatan }\end{array}$ \\
\hline 4 & $\begin{array}{l}\text { Control and se- } \\
\text { curity }\end{array}$ & $\begin{array}{l}\text { a. Terdapat pengontrolan terpusat terhadap penggunaan data. } \\
\text { b. Sistem pengamanan pada sistem informasi pkn teknik informatika umm harus } \\
\text { baik } \\
\text { c. Manajemen dalam memberikan otorisasi dan menentukan pengendalian akses } \\
\text { terhadap penggunaan dan pengoperasian sistem harus jelas } \\
\text { d. Sistem yang digunakan sekarang lebih meringankan pengguna baik dari segi } \\
\text { biaya dan waktu. }\end{array}$ \\
\hline 5. & Efficiency & $\begin{array}{l}\text { a. Penggunaan sistem informasi pkn teknik informatika umm paling berperan da- } \\
\text { lam hal memajukan proses pkn di universitas } \\
\text { b. Sistem dapat mempermudah proses praktek kerja nyata di teknik informatika } \\
\text { universitas muhammadiyah malang } \\
\text { c. Koordinator pkn memberikan bantuan kepada pengguna dalam penggunaan sis- } \\
\text { tem informasi pkn teknik informatika umm. }\end{array}$ \\
\hline 6. & Service & $\begin{array}{l}\text { a. Sistem informasi pkn teknik informatika umm mudah dipelajari dan dipahami } \\
\text { b. Sistem informasi pkn teknik informatika umm mudah digunakan } \\
\text { c. Sistem informasi pkn teknik informatika umm dapat dirubah secara fleksibel } \\
\text { d. Sistem informasi pkn teknik informatika umm terkoordinir dan terintegrasi } \\
\text { dengan sistem yang lain } \\
\text { e. Sistem informasi pkn teknik informatika umm dapat memberikan kepuasan anda } \\
\text { sebagai mahasiswa yang mengerjakan pkn }\end{array}$ \\
\hline
\end{tabular}

